\title{
Epidemiology of Orthopedic Injuries in Indian Cricket: A Prospective One Year Observational Study
}

\author{
${ }^{1}$ Mandeep S Dhillon, ${ }^{2}$ Ritesh K Soni, ${ }^{3}$ Sameer Aggarwal, ${ }^{4}$ Himmat Dhillon, ${ }^{5}$ Sharad Prabhakar
}

\begin{abstract}
Introduction: The understanding of cricket related injuries is still in its infancy in India with very limited surveillance data published from the subcontinent.

Objective: This is a prospective observational study on the epidemiology of orthopedic injuries in Indian cricket players.
\end{abstract}

Materials and methods: This study included cricketers of an elite North Indian cricket team. The study covered a period of 1 year, comprising one playing season and one off season. The player types were categorized by Orchard's injury definitions, and the term 'All Rounder' was introduced.

Results: Ninety-five male players who fulfilled inclusion criteria sustained 48 significant and 12 insignificant injuries. Injury incidence documented by us (3.27 per 10,000 hours of play) was significantly lower than Australian figures (24.2 injuries/10,000 playing hours). These players did not have any 'off day' from the game, leading to limited rest, which was different from international standards. Bowlers sustained the most severe injuries, specifically of the lower limb, while fielders had increased risk of sustaining upper limb injury. Fast bowlers had increased risk of sustaining back trauma. Injuries were also sustained during practice and due to poor ground conditions.

Conclusion: Orchard's internationally accepted definitions of cricket injury need to be modified for the Indian scenario, where 'off days' are not observed, and many injuries which keep players from the game occur in unsupervised practice. This may influence overall incidence and prevalence rates.

Keywords: Cricket injury, Incidence, Observational study, Prevalence, Sports injury.

How to cite this article: Dhillon MS, Soni RK, Aggarwal S, Dhillon H, Prabhakar S. Epidemiology of Orthopedic Injuries in Indian Cricket: A Prospective One Year Observational Study. J Postgrad Med Edu Res 2015;49(4):168-172.

Source of support: Nil

Conflict of interest: None

\footnotetext{
${ }^{1}$ Head, ${ }^{2}$ Former Senior Resident, ${ }^{3}$ Additional Professor

${ }^{4}$ Former MPh Student, ${ }^{5}$ Assistant Professor

1-3,5 Department of Orthopedics, Postgraduate Institute of Medical Education and Research, Chandigarh, India

${ }^{4}$ Department of Physiotherapy, Government Multispeciality Hospital, Chandigarh, India
}

Corresponding Author: Sharad Prabhakar, Assistant Professor, Department of Orthopedics, Postgraduate Institute of Medical Education and Research, Chandigarh, India, Phone: 9781716119, e-mail: sharad.ortho@gmail.com

\section{INTRODUCTION}

Cricket is the most popular sport in India, ${ }^{1}$ and the subcontinent despite being a noncontact sport, injuries in cricket are commonly reported. ${ }^{2,3}$ In Western nations, many studies have documented patterns of cricket related injuries, causative factors and evaluated outcomes of preventive measures in cricket. ${ }^{3}$ The Australian Cricket Board study reported an injury incidence as high as 38.5 injuries per 10,000 player hours in 1 day internationals. ${ }^{3}$ The British Sports Council reported 2.6 injuries per 10,000 hours played in the cricket players surveyed. ${ }^{4}$ South African cricket surveys by Stretch reported data differently, and noted that $49 \%$ of all players injure themselves at some part of the playing season. ${ }^{5,17}$

Despite significant published work from developed countries, minimal data is available from Asian cricket playing nations. The understanding of cricket related injuries is still in its infancy in India, with very little surveillance data published from the country. In fact, only two publications about the incidence of cricket related upper limb injuries and about wicket-keeper's injuries are available from the subcontinent. ${ }^{6,7}$ Thus, a prospective study on epidemiology of orthopedic injuries in Indian cricket players was conducted.

\section{MATERIALS AND METHODS}

This was a prospective study undertaken to document and analyze the pattern of injuries in cricket players of an elite regional North Indian cricket team. The observational study extended from November 2008 for a period of 1 year, comprising one playing season and one off season of 6 months each. The ethical guidelines laid down by Indian Council of Medical Research (ICMR) 2006, the Helsinki declaration (2008), International Ethical Guidelines for Epidemiological Studies as prepared by the Council for International Organizations of Medical Sciences (CIOMS) in collaboration with the World Health Organization (WHO) 2008 were followed. The study was approved by the institute ethics committee vide reference number MS/652/MS3937. Only players who gave an informed consent were included in the study.

The term 'season' was defined as the time period when players played competitive matches whereas 'off season' was defined as the time when players did not 
play competitive level cricket but kept on practicing and often played local matches on weekends.

The players registered with the Punjab Cricket Association (PCA) including the Punjab Ranji Trophy team and the Punjab district teams were included in the study. Players not registered with the PCA, Under 19 team players, Exchange or Guest players and players who refused to give informed consent were excluded.

A detailed written informed consent was taken from each player. All the players associated with these teams were evaluated with the help of coaches, physiotherapists and trainers of the PCA. The player type was defined, categorizing them into four groups:

1. Bowlers, who were further subdivided into fast and slow bowlers. A fast bowler was defined as a bowler for whom the wicket-keeper would normally stand back from the stumps, due to the high speed of the ball when bowled.

2. Batsmen: These were solely in the team due to their batting ability and did not bowl at all.

3. Wicket-keepers, which is a specialized player position.

4. All-rounders, who were players who put equal effort both in bowling and batting during practice, and the match.

These players were followed up regularly during the periodic training camps of PCA. The players were also serially contacted by telephone once every 3 months over one calendar year. The practice profile of the player, any history of injury (including number of days of practice/ number of matches missed) was recorded. A detailed record of the practice profile of each player was also maintained.

All injury definitions were as per the Cricket Australia model defined by John Orchard. ${ }^{8,9}$ Injuries were grouped into 4 groups according to anatomical region: the head, neck and face region, the upper limbs, the back and the trunk, and the lower limbs. The injuries were also grouped as significant and insignificant injuries. Insignificant injuries were categorized as those where players either did not miss any match or they missed $\leq 2$ weeks of practice. ${ }^{8,9}$ The information, thus, obtained was recorded and entered in a computerized data base. (Microsoft Excel, Redland, WA, USA).

Injury incidence was defined as number of injuries occurring in 100 days of exposure and also as injuries per 10,000 hours of play. One day of exposure was defined as being equal to 1 day of match play or 1 day of practice.

Prevalence was calculated as by the following formula: missed player days $\times$ number of injured players / number of play days $\times$ total number of players. Injury prevalence, thus, documented the average number of days these players were unable to play cricket, and included both practice and competitive matches.

\section{OBSERVATION AND RESULTS}

The observational study extended from 1st November 2008 to 31st October 2009. The study included 95 males players fulfilled the inclusion criteria. The average age of the players was 23.24 years (19-34 years). These cricketers had been playing professionally or semi-professionally for an average of 6.8 years (1-15 years) when evaluated. Twenty four cricketers were classified as bowlers, 19 as batsmen, eight as wicket-keepers and the other 44 as allrounders. Among the 24 bowlers, 19 were fast bowlers and five were slow bowlers.

The player practice profile was as follows-Apart from competitive matches, all players had daily practice for specific hours at the PCA stadium Mohali. The training sessions had a uniform format comprising of 2.5 hours of physical training in the morning, followed by 4 hours of game practice in the evening. Standard practice was 6 working days, with official off day on Sunday. However, we noted that most of players played local street or club cricket on Sundays, and so there was no actual 'off day' from the game. The number of hours of cricket practice per week, and per year, are detailed in Table 1.

Over the study period, 60 injuries were documented. The average age of injured players was 23.24 years (19-30 years). Forty eight injuries were classified as 'significant' (43 players, five cricketers having two injuries each) and 12 injuries were classified as 'insignificant'. Our injury calculations were based on these 48 injuries as per Orchard's definitions. ${ }^{6,7}$

During the study period, $38 \%$ of the players were injured. Injury incidence was calculated to be 3.27 per 10,000 hours of play. Injury incidence per 100 days of exposure was $0.18 \%$. The average number of days a player missed practice/matches and was out of active cricket due to injury was 63.81 (21-150 days), which meant more than 2 months away from the game. The injury prevalence in our study was noted to be $10.14 \%$.

The lower limb was most the frequently injured (19 injuries), followed by the upper limb (16 injuries) and the back and trunk (13 injuries). No injury was documented in the head, neck and face.

Among the 19 lower limb injuries, 10 occurred during bowling, four during fielding, four while batting and one while wicket-keeping. There were eight ankle injuries, four knee injuries, five cases of shin pain, and

Table 1: Practice profile of players

\begin{tabular}{ll}
\hline Average No. of hours of daily practice & $5.5 \pm 0.35$ \\
Average No. of days of practice in a week & $5.9 \pm 0.41$ \\
Average No. of weeks of practice in a year & $41.7 \pm 1.9$ \\
Average No. of days of practice in a year & $245.4 \pm 3.1$ \\
Average No. of hours of practice in a year & $1351.9 \pm 6.8$ \\
\hline
\end{tabular}


two phalangeal fractures of the toes. Out of eight ankle injuries, seven were ankle sprains and ligament injuries whereas one player had a fracture of the calcaneus. All the four cases of knee injuries were ligament injuries. One of the cases with shin pain developed into a stress fracture of the distal tibia.

Of the 16 upper limb injuries, 10 were sustained while fielding, four while bowling and two injuries while batting. The injuries were further subdivided as two shoulder injuries, three elbow injuries and 11 injuries to the hand.

There were 13 documented back and trunk injuries. Of these 11 occurred during bowling, one while batting and one bowler injured himself while fielding. Among the 12 bowlers with back pain, seven were fast bowlers and five were slow bowlers. Overall, seven out of 26 fast bowlers had back pain whereas five out of 42 slow bowlers had back pain (p-value 0.019).

\section{DISCUSSION}

Some issues were unique to our study. We noted that injury definitions given by Orchard et $\mathrm{al}^{8,9}$ did not apply fully to the Indian players. By their definition, a player is considered injured only when he misses a significant match or is unable to perform fully due to injury in a particular match. We had some different observations; player practice profile analysis revealed that the PCA players kept on practicing/playing cricket during the so called 'off season' (summer months), thereby increasing the total playing time in one calender year. By Orchard's definitions, 8,9 if a player had a cricket related injury and did not miss a match, he would not be considered injured. For this reason, our study was designed to extend for one full year, and even factored in practice hours lost due to non-match related injuries. The study was, thus, designed to estimate the true incidence of injury with all cricket related activity. The details of injury and the

Table 2: Activity causing injury and the average number of days of practice missed

\begin{tabular}{ll}
\hline Activity causing injury & $\begin{array}{l}\text { Average number of days of practice } \\
\text { missed }\end{array}$ \\
\hline Bowling & $75.66 \pm 2.67$ \\
Fielding & $51.45 \pm 1.86$ \\
Wicket-keeping & $55 \pm 1.93$ \\
Batting & $23 \pm 2.13$ \\
\hline
\end{tabular}

Table 3: Injury incidence according to cricketing activity

\begin{tabular}{lll}
\hline Activity causing injury & Stretch et al ${ }^{11}$ & Our study \\
\hline Batting & $30 \%$ & $14 \%$ \\
Bowling & $47 \%$ & $53 \%$ \\
Fielding & $23 \%$ & $26 \%$ \\
Wicket-keeping & Not reported & $7 \%$ \\
\hline
\end{tabular}

average number of days of practice missed is outlined in Table 2. This particular point has not been documented previously in any study on cricketers, and needs to be factored in for a true calculation of injury data.

The different formats of cricket, the long and the short versions may have some role to play in injury incidence variations. Orchard, ${ }^{10}$ in his editorial in the British Journal of Sports Medicine, has recognized not only the rise of cricket injuries in Twenty Twenty cricket, but also the fact that the first multicountry study has come out 8 years after cricket injury surveillance definitions were standardized.

The injury incidence in our study (3.27 per 10,000 hours of play) was somewhat higher than the British Council report (2.6/10,000 playing hours) ${ }^{4}$ but significantly lower than Australian figures (24.2 injuries /10,000 playing hours). ${ }^{3}$ The high injury incidence in Australians is possibly due to the calculations being based on the injuries sustained only during international and first class matches, with the possibility that elite players play more intense cricket, and therefore, injury rates maybe higher.

In our study, $38 \%$ of cricketers observed injured themselves during the 1 year period. A South African survey ${ }^{5}$ noted that $49 \%$ teenage school boy cricketers sustained injuries in one playing season. The disparity between the two databases may be due to classification of players seeking medical attention as 'injured', resulting in a higher reported injury rate in the South African study. We observed bowling to be the activity that most predisposed to injury; our $53 \%$ bowling related injury rate is similar to the $47 \%$ incidence documented by Stretch ${ }^{11}$ (Table 3).

One finding of note was the $7 \%$ incidence of injuries in wicket keepers; the South African study ${ }^{5}$ did not mention injury occurring specifically to wicket keepers. ${ }^{7}$ Although our database is limited, the study brings into focus these specialized players and further research into overuse injuries and problems with their back and with their hands is needed.

The first international study to use recommended injury surveillance guidelines has been published by Ranson et $\mathrm{al}^{12}$ as a report of five teams competing in the ICC Cricket World Cup in 2011. The authors have reported 23 time-loss and 97 non-time-loss injuries. The injury incidence was 3.7/100 player-days with time-loss incidence for match injury being 20.1/1000 player-days, bowling injury 3.3/100 bowling days and batting injuries 2.2/10,000 balls faced. The authors have stated that non-time-loss injury incidence appears to be high and further investigations for progression to time loss are required. This subgroup is comparable to the group of insignificant injuries in our series; none of our cases progressed to an injury which involved significant time loss. 
Interestingly both fast and slow bowlers had a similar injury prevalence of about $5 \%$. This is in contrast to our study in which seven out of 26 fast bowlers had back pain whereas five out of 42 slow bowlers had back pain (p-value 0.019).

In our study, there was no injury to the head, neck and face. One reason could be the fact that all players were using some form of protective head gear during both practice and matches. This is in contrast to Ranson et $\mathrm{al}^{13}$ data on the ICC cup, where significant head and facial injuries involved batsmen. The authors reported that $30 \%$ of these injuries occurred due to the ball penetrating the gap between the helmet peak and faceguard. They have suggested improving the cricket helmet design. This disparity can be explained by the higher bowling speeds of these international bowlers, in pace friendly conditions, compared to the more benign pitches and slower bowlers of state teams of the Punjab. This assumption, however, needs confirmation with further studies.

The injury prevalance rate in our study was $10.4 \%$ which is higher than the injury prevalence rate of $7.8 \%$ as reported by Orchard et al. ${ }^{3}$ Our figure of 'total cricket playing days' lost (63.81) could not be compared with any of the previous international studies. This is because both match days and practice days were included by us to get a true idea of total cricket playing time.

Our study also introduced of the term 'all-rounder' for purposes of player classification. This was done as modern shorter versions of cricket lay a lot of emphasis on inclusion of all-rounders in a team. Most all-rounders are batsmen who can bowl a bit, mostly slow spin bowling; some bowlers on the other hand exhibit more than average batting skills. However, on comparing the incidence of injury in all-rounders and other players, the difference was not statistically significant.

We noted 13 episodes of back pain in the bowlers, 11 of which were sustained during the act of bowling. Seven of 26 fast bowlers reported back pain whereas only five out 42 slow bowlers complained of back pain during this period ( $p$-value 0.019). This reiterates the fact that low back injury and pain is more common in fast bowlers; similar findings were documented by Gregory et $\mathrm{al}^{14}$ in English fast bowlers. Morton et $\mathrm{al}^{15}$ further identified risk factors and successful interventions for cricket related low back pain; they emphasized that screening for bone stress on MRI should be considered by physicians managing developing cricketers to identify the risk of lumbar stress fracture development. Oliver et $\mathrm{al}^{16}$ have also emphasized that lumbar position sense, as a measure of proprioception, was related to injuries sustained during the bowling action, especially low back injury sustained in the past. They stressed that if proprioception of the lumbar spine is significantly improved in pace bowlers, the risk of lumbar injury can potentially be reduced.

Our data showed that the lower limb was most vulnerable to injuries in cricketers (45\% of total injuries). Similar findings have been previously documented by Leary et $\mathrm{al}^{18}$ (44.9\% of total injuries) and Stretch et $\mathrm{al}^{19}$ (49.8\% of total injuries). Bowling was the major cause of injuries to the lower limb as out of 19 lower limb injuries, $10(53 \%)$ were sustained during bowling. Ranson et $\mathrm{al}^{12}$ has recognized thigh muscle strain as being one of the the diagnoses with the highest incidence.

We encountered 16 (16.6\%) upper limb injuries, 10 of which occurred during fielding, four during bowling, and two during batting. Similar findings have been documented by Leary et $\mathrm{al}^{18}(29.4 \%)$, Stretch ${ }^{19}$ (24.6\%), Finch et $\mathrm{al}^{20}(32.6-33.9 \%)$.

One unique finding in our study was that we documented injuries to cricketers due to poor ground conditions.; three such avoidable injuries were noted. One had sudden twisting of right ankle joint when his foot was caught in a sprinkler. The second player, a wicketkeeper sustained injury to his left arm while diving on the ground and a metal rod penetrated and injured his left arm.The third player twisted his ankle joint when his foot was trapped in a hole on the ground. No other study from the developed world has documented this, and it becomes pertinent in young cricketers practicing in suboptimal conditions.

Certain limitations were very apparent in our study. Since there was no system for recording injuries on the ground in the prevailing set up, there was poor documentation of injuries when players were not under our direct supervision. These players were not necessarily local city based, and often went back to their hometowns and continue to play/practice cricket. In this scenario, it is quite possible that we might have missed some of the injuries sustained in this 1 year period; this may be one of the reasons our reported injury incidence is lower than that of the Australian or South African studies.

One hypothesis for low incidence of injuries in this study maybe the better sustained physical conditioning of our players. Most of our players kept on practicing throughout the year, and this heightened physical fitness level may be one factor in increasing their injury threshold, thus minimizing some injuries that often occur in the pre-season training and early season games. However, further studies are needed to substantiate this hypothesis.

\section{CONCLUSION}

- The incidence of cricket injuries in Indians is significant, causing them to miss cricket matches or practice for a significant number of days. 
- Severity of injury sustained during bowling, as judged by the number of practice days missed, was more than the injury sustained during fielding, batting or wicket keeping.

- Fielders have an increased risk of sustaining upper limb injury, while bowlers have an increased risk of sustaining lower limb injury. Bowlers, especially fast bowlers have increased risk of sustaining back injury.

- Poor ground conditions in developing countries can result in serious injuries, causing considerable loss of cricket time.

\section{PRACTICAL IMPLICATIONS}

- The study highlights the importance of having a regular, systematic injury surveillance program for cricket players with proper documentation and follow-up. This would help to minimize loss of match playing days by ensuring timely diagnosis and appropriate treatment measures.

- Assessment of common injury patterns enables trainers and physiotherapists to institute appropriate preventive training strategies.

- Western definitions of sports injury need to be modified to be fully applicable to the Indian setup, so as to include non-match day cricket. This would enable accurate assessment of injury data.

\section{REFERENCES}

1. Finch CF, Elliott BC, McGrath AC. Measures to prevent cricket injuries. Sports Med 1999;28(4):263-272.

2. Bowen R. Cricket, a history of its growth and development throughout the world. London: Eyre and Spottiswoode; 1970. p. 150.

3. Orchard J, James T, Alcott E, et al. Injuries in Australian cricket at first class level 1995/96 to 2000/2001. Br J Sports Med 2002;36(4):270-275.

4. Weightman D, Browne RC. Injuries in eleven selected sports. Br J Sports Med 1975;9(3):136-141.
5. Stretch RA. Incidence and nature of epidemiological injuries to elite South African players. S Afr Med J 2001;91(4):336-339.

6. Dhillon MS, Garg B, Soni RK, et al. Nature and incidence of upper limb injuries in professional cricket players; a prospective observation. Sports Med Arthrosc Rehabil Ther Technol 2012 Nov 8;4(1):42.

7. Dhillon MS, Prabhakar S, Raj N. The Wicketkeeper and Injury. J Postgrad Med Educat Res 2013 April-June;47(2):99-102.

8. Orchard J, Newman D, Stretch R, et al. Methods of injury surveillance in international cricket. South African J Sports Med 2005;17(2):18-28.

9. Orchard J, Newman D, Stretch R, et al. Defining a cricket injury. J Sci Med Sport 2005;8(3):358-359.

10. Orchard JW. Injury surveillance in cricket. Br J Sports Med 2013;47(10):605-606.

11. Stretch RA. The seasonal incidence and nature of injury in school boy cricketers. S Afr Med J 1995;85(11):1182-1184.

12. Ranson C, Hurley R, Rugless L, et al. Intenational Cricket injury surveillance: a report of five teams competing in the ICC Cricket world cup 2011. Br J Sports Med 2013 Jul;47(10): 637-643.

13. Ranson C, Peirce N, Young M. Batting head injury in professional cricket: a systematic video analysis of helmet safety characteristics. Br J Sports Med 2013 Jul;47(10):644-648.

14. Gregory P, Bratt M, Wallace WA. Comparing injuries of spin bowling with fast bowling in young cricketers. Clin J Sports Med 2002;12(2):107-112.

15. Morton S, Barton CJ, Rice S, et al. Risk factors and successful interventions for cricket-related low back pain: a systematic review. Br J Sports Med 2014 Apr;48(8):685-691.

16. Oliver B, Stewart AV, McKinon W. Injury and lumbar reposition sense in cricket pace bowlers in neutral and pace specific bowling specific body positions. Spine J 2013 Nov 21. pii: S1529-9430(13)01483-6.

17. Stretch RA. The incidence and nature of injuries in first-league and provincial cricketers. S Afr Med J 1993;83(5):339-342.

18. Leary $\mathrm{T}$, White J. Acute injury incidence in professional county club cricket players (1985-1995). Br J Sports Med 2000;34:145-147.

19. Stretch RA. Cricket injuries: a longitudinal study of the nature of injuries to South African cricketers. Br J Sports Med 2003;37(3):250-253.

20. Finch C, Valuri G, Ozanne-Smith J. Sport and active recreation injuries in Australia: evidence from emergency department presentations. Br J Sports Med 1998;32(3):220-225. 